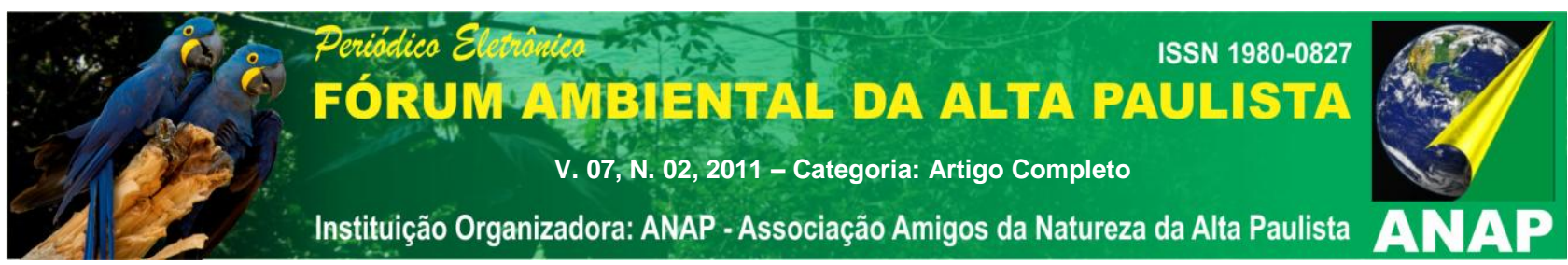

\title{
GEOTECNOLOGIAS APLICADAS NA IDENTIFICAÇÃO DE APP (ÁREA DE PROTEÇÃO PERMANENTE) DE NASÇENTES NO CORREGO DAS CRUZES - SELVÍRIA (MS).
}

\author{
Renan De Almeida Silva ${ }^{1}$ \\ Eduardo Vinicius Rocha Pires ${ }^{2}$ \\ Flavia Joise Izippato ${ }^{3}$ \\ Patrícia Helena Mirandola ${ }^{4}$
}

RESUMO: Este trabalho se enquadra dentro do projeto maior que estuda a bacia hidrográfica do Rio Sucuriú, financiado pelo CNPq (Conselho Nacional de Desenvolvimento Cientifico e Tecnológico). A bacia hidrográfica do Córrego das Cruzes localiza-se a sudoeste do município de Selvíria - MS, entre coordenadas geográficas $20^{\circ} 31^{\prime} 02^{\prime \prime} \mathrm{S}$ e $20^{\circ} 16^{\prime} 06^{\prime \prime} \mathrm{S}$ e $52^{\circ} 01^{\prime} 46^{\prime \prime} \mathrm{W}$ e $51^{\circ} 48^{\prime} 29^{\prime \prime} \mathrm{W}$, abrangendo uma área de aproximadamente 224 $\mathrm{Km}^{2}$ Os recursos hídricos sofrem pressões cada vez maiores à medida que aumentam as ações antrópica sobre seu leito e margens. As funções das Áreas de Preservação Permanente (APP), além de impedir a erosão e assoreamento dos rios, também estabelecem condições apropriadas à manutenção do volume de água e o desenvolvimento da biodiversidade. No caso deste projeto, as geotecnologias vêm nos atender com informações e dados obtidos por meio de sensores orbitais que obtém imagens da superfície terrestre, Sensoriamento Remoto e Sistemas de informação Geográfica. Para a delimitação das APP's no entorno das nascentes, foram utilizadas como referência o Código Florestal Brasileiro, no artigo 2ํㅡ da Lei ํo 4771 de 15 de Setembro de 1965 e especificadas pela Resolução n 302 do Conselho Nacional do Meio Ambiente (CONAMA), na data de 20 de março de 2002, que discrimina um raio de 50 metros no entorno das nascentes. Por fim, foram

${ }^{1}$ Graduando em geografia - UFMS/CPTL. Bolsista de iniciação científica PIBIC - CNPq e membro do DIGEAGEO (Diretrizes de Gestão Ambiental com Uso de Geotecnologias). Email: geo.renanalmeida@gmail.com

${ }^{2}$ Graduando em geografia - UFMS/CPTL. Bolsista de iniciação científica PIBIC - CNPq e membro do DIGEAGEO (Diretrizes de Gestão Ambiental com Uso de Geotecnologias). Email: drocha.geo@gmail.com

${ }^{3}$ Mestranda do Programa de Pós-graduação em geografia UFMS/CPTL. Bolsista Capes e membro do DIGEAGEO (Diretrizes de Gestão Ambiental com Uso de Geotecnologias). Email: flaviajoise@gmail.com

${ }^{4}$ Docente do Programa de Pós-graduação em geografia - UFMS/CPTL. Líder do grupo DIGEAGEO (Diretrizes de Gestão Ambiental com Uso de Geotecnologias). Email: patriciaufmsgeografia@gmail.com 


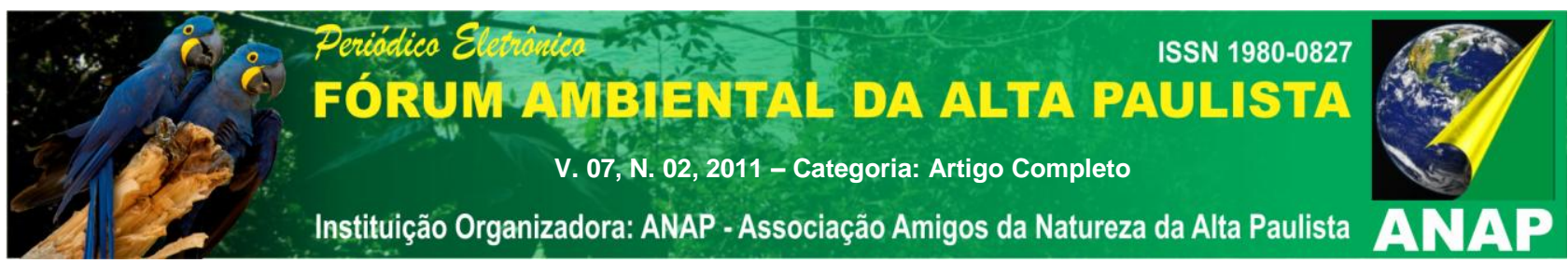

mapeadas 16 nascentes presentes na BHCC, onde a maioria situa-se em área de pastagem, o que gera preocupações devido a criações de gados.

Palavras chave: Geotecnologia. APP. Bacia Hidrográfica.

\section{INTRODUÇÃO}

O presente trabalho é uma parte componente de um projeto maior que estuda a Bacia Hidrográfica do Rio Sucuriú, financiado pelo CNPq (Conselho Nacional de Desenvolvimeto Cientifico e Tecnológico), para atender aos objetivos propostos no projeto maior. Este subprojeto visa identificar e analisar a situação atual da Bacia Hidrográfica do córrego das Cruzes, que é um dos afluentes do Rio Sucuriú, fazendo uma análise integrada dos componentes ambientais existentes e identificando o uso e a ocupação do espaço correlacionando os dados de declividade, hipsometria, hidrografia, geologia, pedologia, geomorfologia, através de técnica de geoprocessamento e utilização de imagens de satélites.

O crescimento urbano desenfreado e a interferência humana mostram a importância de estudos voltados ao dinamismo da paisagem envolvente, a ação antrópica correlacionado com o meio natural urge medidas de planejamento, uma vez que modificado pelo homem traz diversos problemas sociais, culturais e ambientais. Deste modo, medidas de mitigação dos problemas relacionados, homem x natureza é de tamanha importância para o estudo da ciência Geográfica e as demais ciências.

Mirandola-Avelino (2006) afirma que para que haja a possibilidade de se efetivar uma proposta de avaliação ambiental, muitas etapas de pesquisa devem ser realizadas em uma determinada área, região, bacia hidrográfica, município ou qualquer outra forma de delimitação operacional, buscando atender a vários objetivos, dentre eles os diagnósticos e prognósticos ambientais.

No Brasil, os primeiros parâmetros sobre preservação entraram em vigor com o Código Florestal Brasileiro de 1965. Assim constituíram APP's como espaços físicos legalmente protegidos, estando devidamente definidos nos termos dos Artigos $2^{\circ}$ e $3^{\circ}$ da Lei 4.771/65 (Código Florestal). Estas áreas, em geral são cobertas por vegetação nativa, que 


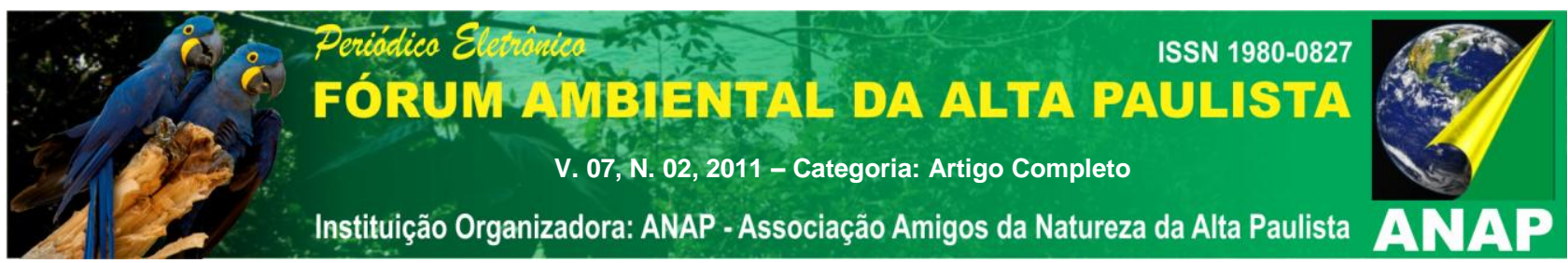

provem da função ambiental de preservar os recursos hídricos, a paisagem, a estabilidade geológica, a biodiversidade, o fluxo gênico de fauna e flora, proteger o solo e assegurar o bem estar das populações.

A proeminência do levantamento do planejamento de ocupação espacial se faz necessária para melhor salientar problemas futuros e impedindo muitas vezes, prejuízos maiores tanto para a sociedade quanto para o meio ambiente.

Neste sentido, o Sensoriamento Remoto e o Geoprocessamento, remetem papéis importantes no entendimento dos recursos naturais. O Sensoriamento Remoto permite uma maior aquisição de informações sobre a superfície terrestre, detectando e registrando a imagem e/ou o objeto sem que haja contato direto com os mesmo.

O Sistema de Informação Geográfica permite a integração da área de estudo com as mudanças ocorridas, através de uma analise multitemporal essas alterações podem sugerir diretrizes de uso e ocupação da área.

\section{Localização Sistêmica da área de estudo}

A bacia hidrográfica do Córrego das Cruzes (BHCC) localiza-se a sudoeste do município de Selvíria - MS, entre coordenadas geográficas $20^{\circ} 31^{\prime} 02^{\prime \prime}$ S e $20^{\circ} 16^{\prime} 06^{\prime \prime}$ S e $52^{\circ} 01^{\prime} 46^{\prime \prime}$ W e $51^{\circ} 48^{\prime} 29^{\prime \prime}$ W, abrangendo uma área de aproximadamente $224 \mathrm{Km}^{2}$ (Figura 1).

O canal principal do Córrego das Cruzes, conforme a definição de Horton (apud Christofoletti 1980) classifica-se como um canal de '3. ' (Terceira) Ordem', já que recebe afluência de outros córregos, os de primeira e segunda ordem (figura 1).

Tendo em vista a abordagem sistêmica que fora tomada, a BHCC faz parte de um sistema maior, no qual se denomina de Bacia do Rio Paraná, que tem como afluente a Bacia do Rio Sucuriú, subsistema onde se deságua a parte componente Bacia Córregos das Cruzes. 


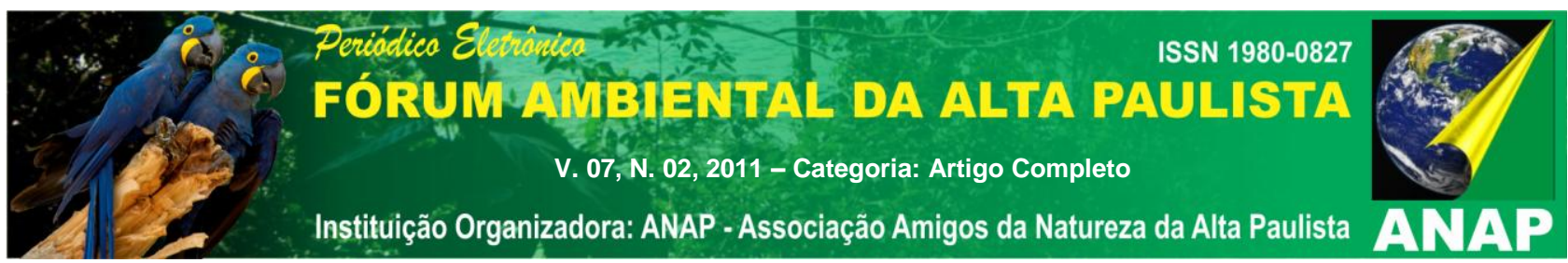

Tendo como apoio a Teoria Geral dos Sistemas a presente análise esta estruturada da seguinte forma:

- Bacia Hidrográfica do Rio Paraná - Sistema

- Bacia Hidrográfica do Rio Sucuriú - Subsistema

- Bacia Hidrográfica do Córrego das Cruzes - Partes Componentes

LOCALIZAÇÃO SISTEMICA DA BHCDT

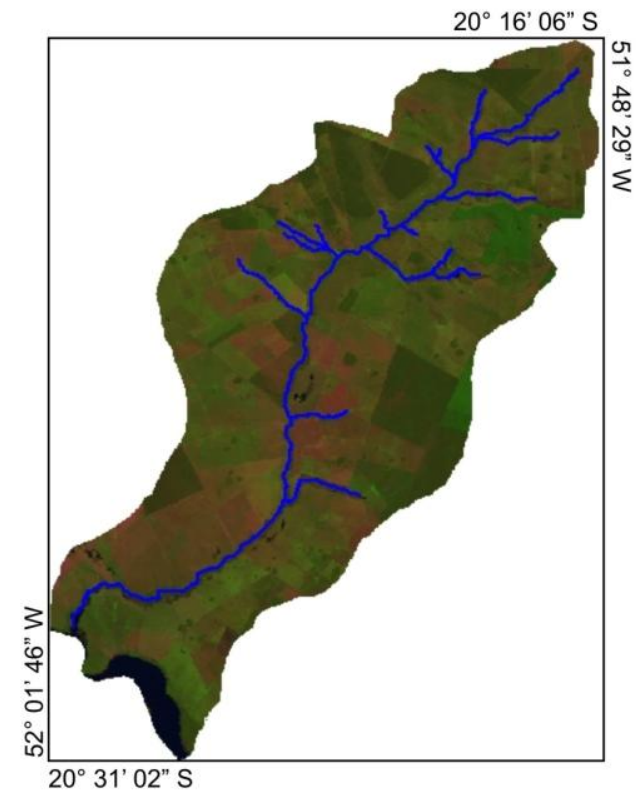

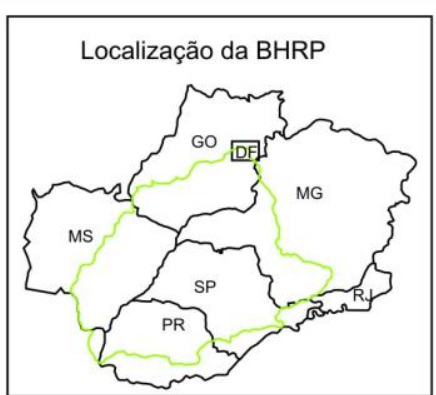
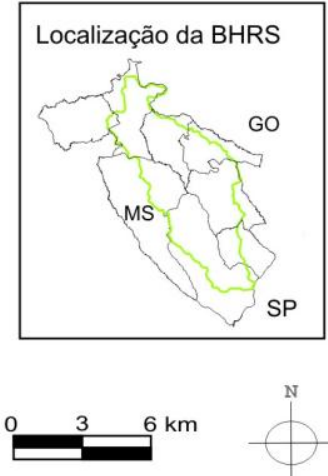

UFMS - Universidade Federal de Mato Grosso do Sul. UFMS

Fonte: Imagem de satélite Landsat 5 sensor TM orbita 223 Ponto 074 Sistema de Projeção Polyconic Datum Sirgas 2000. Orcanização Edição: SILVA, Renan Almeida (2011)

Digeageo: Diretrizes de Gestão Ambiental com (BOAde Geotecnologias Lapegeo: Laboratório de Prática e Geoprocessamento.

Figura 1: Localização da área de estudo

\section{FUNDAMENTAÇÃO TEÓRICA}




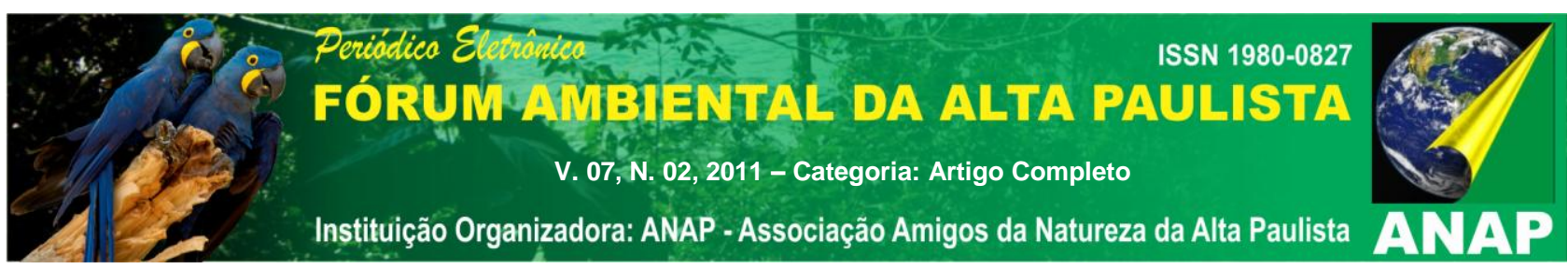

A ação antrópica na apropriação e exploração do espaço geográfico acarreta significativas transformações ambientais e sociais. O homem como ser social interage com o meio ambiente modificando e transformando, isto é, buscando novas possibilidades e modalidades de utilização do espaço de acordo com seus interesses. Essa dinâmica refletese nos processos de degradação ambiental, provocadas por diversas atividades como agricultura, pecuária, urbanização, construção de estradas e mineração.

A incessante ação humana de explorar cada vez mais os recursos naturais motivadas pela necessidade de desenvolvimento econômico tem ultrapassado os limites das normalidades de uso e ocupação do solo. O resultado dessa prática "Desenvolvimentista" tem acarretado em muitas situações a falta de observação das normas adequadas, ou seja, sem planejamento, o que acaba ocasionando uma degradação rápida dos recursos naturais, sendo que a deterioração do meio ambiente está diretamente associada ao sistema econômico de exploração do solo.

Os cenários ambientais construídos ou transformados pela ação do homem ocupam a maior parte dos sistemas ambientais. O homem transforma os espaços através de derrubadas de matas, da implantação de pastagens e cultivos, da construção de estradas, portos aeroportos, represas, da retificação e canalização de curso d água, da implantação de indústrias e áreas urbanas.(FLORENZANO, 2002).

Os processos naturais como erosão e modificação da cobertura vegetal, independente da ação humana, ocorrem de forma natural. Entretanto, quando o homem transforma o ambiente, esses processos são acelerados, tendo consequências imediatas no mau uso deste solo.

Essa problemática tem sido foco de diversos estudos relacionados à temática ambiental e da Geografia Física, pois está relacionado diretamente com o processo de erosão que ocorre dentro do sistema bacia hidrográfica.

Compreende-se que um estudo de bacias hidrográficas deve ser entendido por visões integradas na qual se deve transcender os conhecimentos fragmentados das diferentes áreas do conhecimento. Deste modo, ao estudar os diversos componentes de uma 


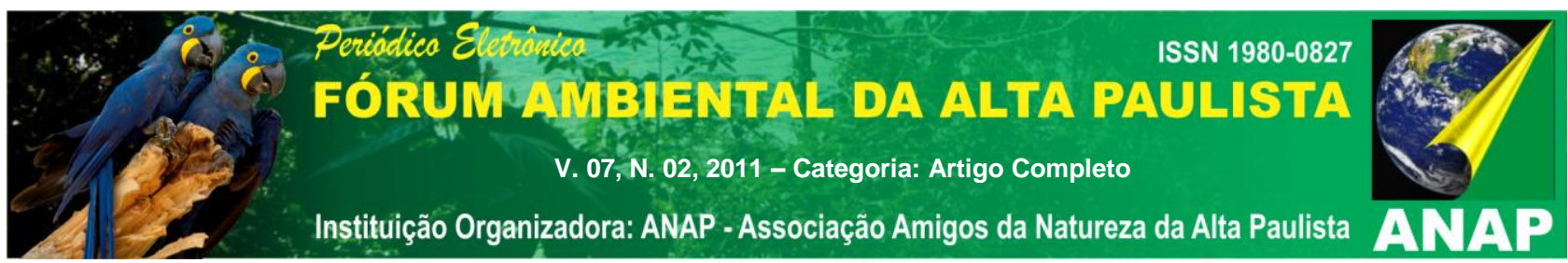

bacia hidrográfica, torna possível contemplar diversos aspectos do meio natural de uma maneira holística ou sistêmica.

Um sistema de drenagem é considerado para Chorley (1962) e Coelho Netto (1995) apud Cunha e Guerra (2003), um sistema aberto onde ocorre a entrada e saída de energia. As bacias de drenagem recebem energia fornecida pela atuação do clima e da tectônica locais (input), eliminando fluxos energéticos pela saída da água, sedimentos e solúveis (output).

A remoção da vegetação natural nas encostas, causada pela ação do homem, ocasiona uma mudança da dinâmica do ambiente que antes se encontrava em um equilíbrio, assim, ficando suscetível aos processos erosivos.

O presente trabalho apoia-se no enfoque sistêmico, como referencial para a integração dos componentes geoambientais e socioeconômicos, que formam o conjunto da Bacia Hidrográfica do Rio Sucuriú, considerado como um subsistema ambiental e a Bacia Hidrográfica do Córrego das Cruzes sua parte componente.

Conduzidos por esta concepção, os estudos descartam a abordagem meramente setorial que enfatiza cada componente individualmente, seja a vegetação, a água, os minerais, seja o próprio homem, detendo-se na análise integrada e correlações guiadas pelos princípios de interdisciplinaridade.

A metodologia sistêmica consiste em analisar o ambiente de forma holística considerando os níveis de análises como sendo o morfológico, encadeante, processoresposta e controle.

O conceito de Áreas de Preservação Permanente (APP) presente no código Florestal brasileiro (Lei 4.771 de 15/09/1965) emerge do reconhecimento da importância da manutenção da vegetação de determinadas áreas - as quais ocupam porções particulares de uma propriedade, não apenas para os legítimos proprietários dessas áreas, mas, em cadeia, também para os demais proprietários de outras áreas de uma mesma comunidade, de comunidades vizinhas, e finalmente, para todos os membros da sociedade. 


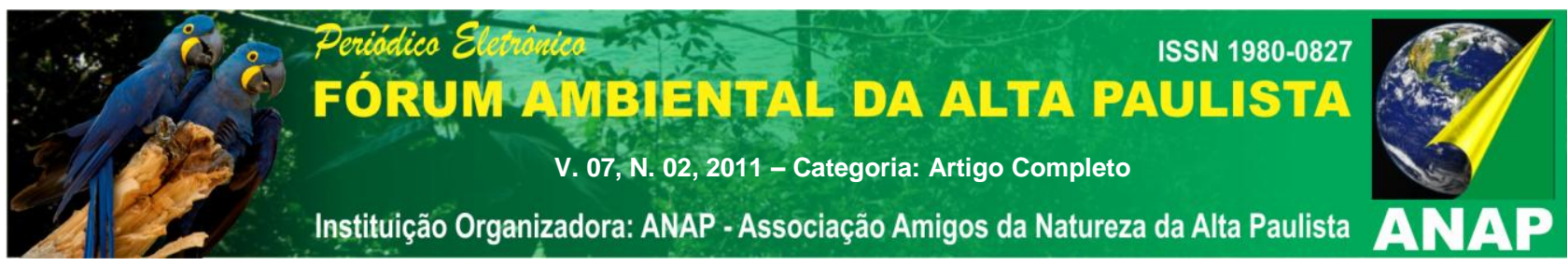

No que se refere às APP's, o código florestal apresenta oito categorias passiveis de serem delimitadas de acordo com fatores hidrológicos e com aspectos naturais da paisagem em conformidade com a disposição e a caracterização geomorfológica do ambiente.

Tomando como base o Código Florestal Brasileiro, no artigo 늘 da Lei n 4771 de 15 de Setembro de 1965 e especificadas pela Resolução n 302 do Conselho Nacional do Meio Ambiente (CONAMA) na data de 20 de março de 2002, no caso das nascentes, o código discrimina um raio de 50 metros de proteção ao seu entorno.

Entende-se que sua importância física nas áreas de nascente, consiste na atuação da vegetação como amortecedor das chuvas, evitando o seu impacto direto sobre o solo e a sua paulatina compactação.

Atuando juntamente com toda a massa formada por raízes das plantas, admite que o solo permaneça poroso e capaz de absorver a água das chuvas, permitindo sua infiltração nos lençóis freáticos, que por sua vez, evita o escoamento superficial excessivo de água, responsável pelo carregamento de partículas de solo e resíduos tóxicos provenientes das atividades agrícolas para o leito dos cursos d'água (EMBRAPA, 2006).

O uso das geotecnologias (Sensoriamento Remoto, Geoprocessamento, GPS, Cartografia automatizada, Sistema de informação geográfica) nos permite fazer uma análise integrada do ambiente de forma a entender como questões relacionadas às alterações ambientais se comporta no espaço, esse é um dos pontos fortes permitindo que o ambiente seja estudado em parte e entendido como um todo.

As geotecnologias podem ser entendidas como as novas tecnologias ligadas às geociências e correlatas, as quais trazem avanços significativos no desenvolvimento de pesquisas, em ações de planejamento, em processos de gestão, manejo e em tantos outros aspectos relacionados à estrutura do espaço geográfico. Essas considerações tornam-se importantes à medida que profissionais das mais diversas áreas atuam diretamente com questões espaciais. Entretanto, a interatividade necessária para que se possa trabalhar o meio ambiente como um todo, de forma interdisciplinar, torna necessária uma busca por ferramentas e técnicos qualificados para sua concretização. A inserção de profissionais de diferentes áreas do conhecimento, com destaque para o geógrafo, torna-se essencial para um bom resultado dos trabalhos desenvolvidos (FITZ, 2008, p.11). 


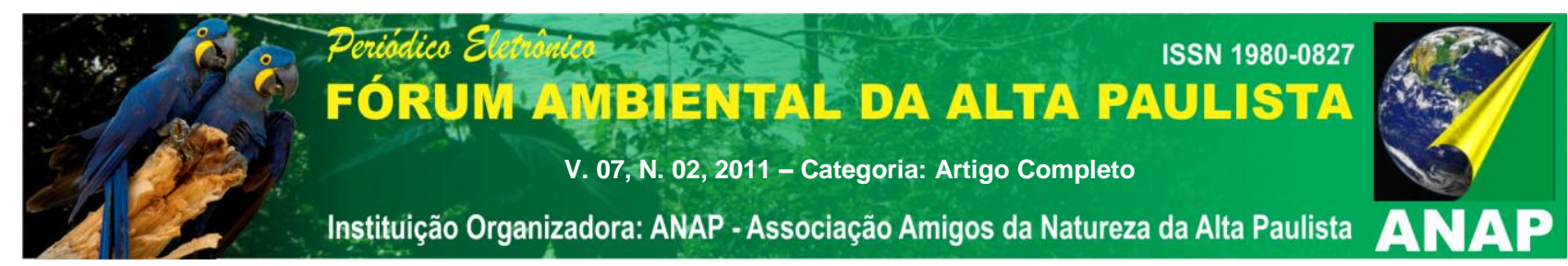

O objetivo dessa pesquisa foi avaliar e demonstrar a importância dessas geotecnologias na análise do uso e ocupação da terra e APPs de nascentes, já que atualmente os sistemas de informações geográficas (SIG) vêm ganhando espaço dentro dos órgãos públicos e privados. Mapas digitais vinculados a bancos de dados e imagens de satélites tem sido uma importante ferramenta no auxilio a gestão e tomada de decisões.

\section{MATERIAIS E MÉTODOS}

Para Atingir os objetivos da pesquisa foram utilizados os seguintes materiais: imagens do Satélite Landsat 5 (Land Remote Sensing Satellite) órbita 223 e ponto 74, sendo uma do ano de 2000 (02 de Abril de 2000) e 2011 (20 de junho de 2011). Utilizou-se também software SPRING ${ }^{\circledR} 5.1 .7$ (Instituto Nacional de Pesquisas Espaciais), Corel Draw ${ }^{\circledR} 12$, Word ${ }^{\circledR}$ e Excel ${ }^{\circledR}$.

A primeira etapa dos procedimentos operacionais foi à criação de um banco de dados, projeto, categoria (modelos: imagem, cadastral e temático) e planos de informações, com fases: elaboração da melhor composição colorida e realce, registro, segmentação, classificação supervisionada utilizando o classificador Bhattacharya. No processo de segmentação utilizou-se o método de crescimento de regiões, com similaridade 10 pixel e área 08 pixel. Para chegar nesse parâmetro de similaridade e área foram realizados testes, nos quais os alvos da superfície terrestre de interesse foram detectados em forma de regiões. Depois da segmentação, foi utilizado o classificador Bhattacharya onde a medida de distância é usada neste classificador por regiões, para medir a separabilidade estatística entre um par de classes espectrais, com liminar de aceitação de 99,9\% para o mapeamento do uso e ocupação da terra da bacia hidrográfica do Córrego das Cruzes.

Adotou-se proposta pelo Instituto Nacional de Pesquisas Espaciais (INPE) para o processamento digital das imagens. A Partir de análise visual em gabinete, determinaram-se 


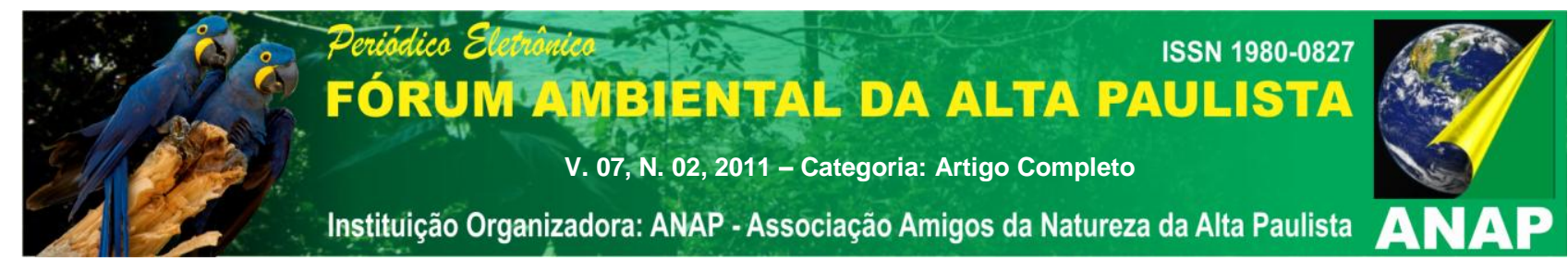

as classes de uso da terra existente na bacia, sendo elas: Pastagem, Silvicultura, Vegetação Natural Florestal, Vegetação Natural Campestre e Água Continental.

Para a confecção do mapa de uso e ocupação da terra, utilizou-se o método proposto pelo IBGE no Manual do Uso da Terra. O manual apresenta o desenho esquemático dos fluxos existentes no processo de levantamento e classificação da Cobertura e do Uso da Terra além de propor cores na legenda do mapa de uso e ocupação da terra do município de Ribas do Rio Pardo (Quadro 1).

Quadro 1: Cores e classes do Uso e Ocupação da Terra

\begin{tabular}{|c|c|c|}
\hline Nivel I & & Nivel II \\
\hline \multirow{2}{*}{$\begin{array}{l}\text { 1. Areas Antrópicas } \\
\text { Năo Agrícolas }\end{array}$} & 1.1 & Área Urbanizada \\
\hline & 1.2 & Área de Mineraçăo \\
\hline \multirow{4}{*}{$\begin{array}{l}\text { 2. Area Antrópicas } \\
\text { Agricolas }\end{array}$} & 2.1 & Cultura Temporária \\
\hline & 2.2 & Cultura Permanente \\
\hline & 2.3 & Pastagem \\
\hline & 2.4 & Silvicultura \\
\hline \multirow{2}{*}{$\begin{array}{l}\text { 3. Areas de } \\
\text { Vegetaçăo Natural }\end{array}$} & 3.1 & Florestal \\
\hline & 3.2 & Campestre \\
\hline \multirow{2}{*}{ 4. Agua } & 4.1 & Corpos d̛água continentais \\
\hline & 4.2 & Corpos d'água costeiros \\
\hline
\end{tabular}

Para a delimitação das APP's no entorno das nascentes, foram utilizadas como referência o Código Florestal Brasileiro, no artigo $2^{\circ}$ da Lei $n^{\circ} 4771$ de 15 de Setembro de 1965 e especificadas pela Resolução $n^{\circ} 302$ do Conselho Nacional do Meio Ambiente 


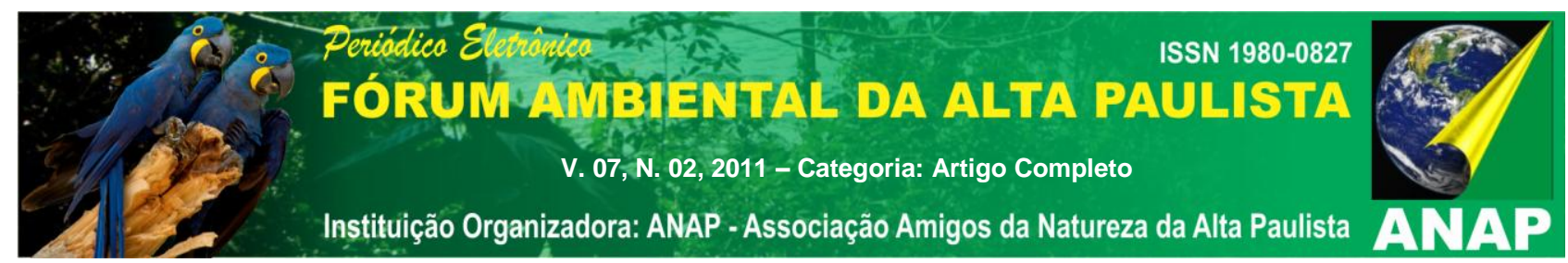

(CONAMA), na data de 20 de março de 2002, que discrimina um raio de 50 metros no entorno das nascentes.

Assim, foram demarcados os pontos centrais das nascentes em cada ponta que inicia uma drenagem com a ferramenta "Edição Vetorial", posteriormente, utilizando a função "Mapa de Distâncias", foram delimitadas com um raio de $50 \mathrm{~m}$, todas as nascentes que ocorrem na bacia.

Para finalização dos pontos, adotou-se nome a cada nascente para fins de identificação e elaboração de diagnósticos distintos uma das outras.

\section{RESULTADOS E DISCUSSÕES}

No processo de classificação da imagem e posterior elaboração de mapas temáticos, considerou-se apenas áreas maiores que $900 \mathrm{~m}^{2}$ devido à resolução espacial da imagem utilizada. Na classe temática vegetação natural florestal, considerou-se áreas florestais, áreas de reserva legal e matas ciliares. Obteve-se também no mapeamento a classe pastagem, caracterizada pela presença de gramíneas destinadas a nutrição animal e a classe vegetação natural campestre, onde também é utilizada pelos pecuaristas como local de criação bovina. Em água continental, houve o predomínio do córrego das Cruzes, lagos e lagoas, por fim, ouve a presença da classe silvicultura que alem da pecuária é outro fator forte para a economia da cidade onde está inserida a bacia hidrográfica.

Para obter uma análise ampliada e acompanhar a dinâmica de transformação do ambiente naquele local, foram analisados o uso e ocupação da bacia hidrográfica em imagens de satélites de anos distintos, assim alcançando um acompanhamento da dinâmica de transformação da paisagem (Figura 2). 


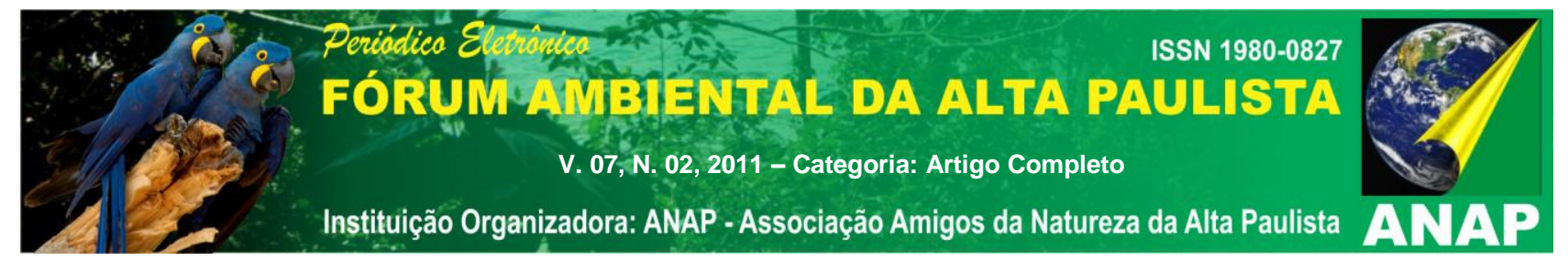

MAPA DE USO E COBERTURA DA TERRA DO MUNICÍPIO DE TRÊS LAGOAS/MS.

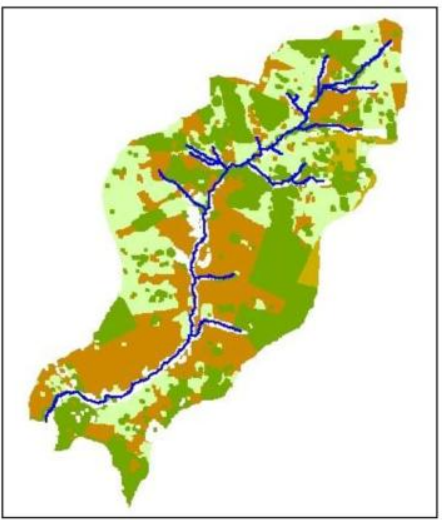

USO DA TERRA EM 2000.

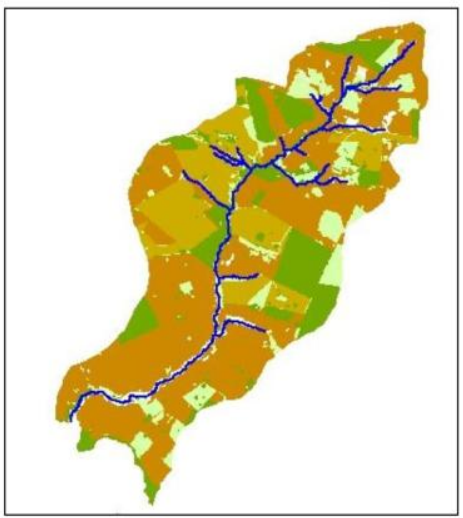

USO DA TERRA EM 2011.

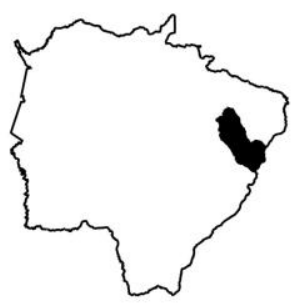

Legenda

$\square$ Corpo D'água continental

Silvicultura

Area Urban

Pastagem

Área Ủmic

Vegeçao Natural Campestre

Vegetação Natural Florestal

UFMS - Universidade Federal de Mato Grosso do Sul. Fonte: Imagem de satellite Landsat 5 sensor TM Orbita 223 Pon

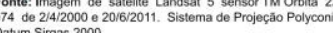

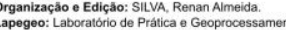

Figura 2 - Uso e ocupação do solo no ano de 2000 e 2011.

Tabela 2: Uso e ocupação do solo no ano de 2000 e 2011

\begin{tabular}{|c|c|c|c|c|}
\hline \multirow{2}{*}{ CLASSES } & \multicolumn{2}{|c|}{2000} & \multicolumn{2}{|c|}{2011} \\
\cline { 2 - 5 } & \multirow{2}{*}{ ÁREA (KM ${ }^{2}$ ) } & PORCENTAGEM (\%) & \multirow{2}{*}{ ÁREA (KM ${ }^{2}$ ) } & PORTENTAGEM (\%) \\
\hline PASTAGEM & 78.83 & 35.19 & 88.17 & 39,36 \\
\hline SILVICULTURA & 5.74 & 2,56 & 34.01 & 15.18 \\
\hline CAMPESTRE & 60.91 & 27.19 & 41.32 & 18.44 \\
\hline AREA VEG NATU FLORESTAL & 61.05 & 27.25 & 50.71 & 22.63 \\
\hline CORPOS D'AGUA CONTINENTAIS & 16.93 & 7.55 & 9.77 & 4,36 \\
\hline TOTAL & 224 & 100 & 224 & 100 \\
\hline
\end{tabular}



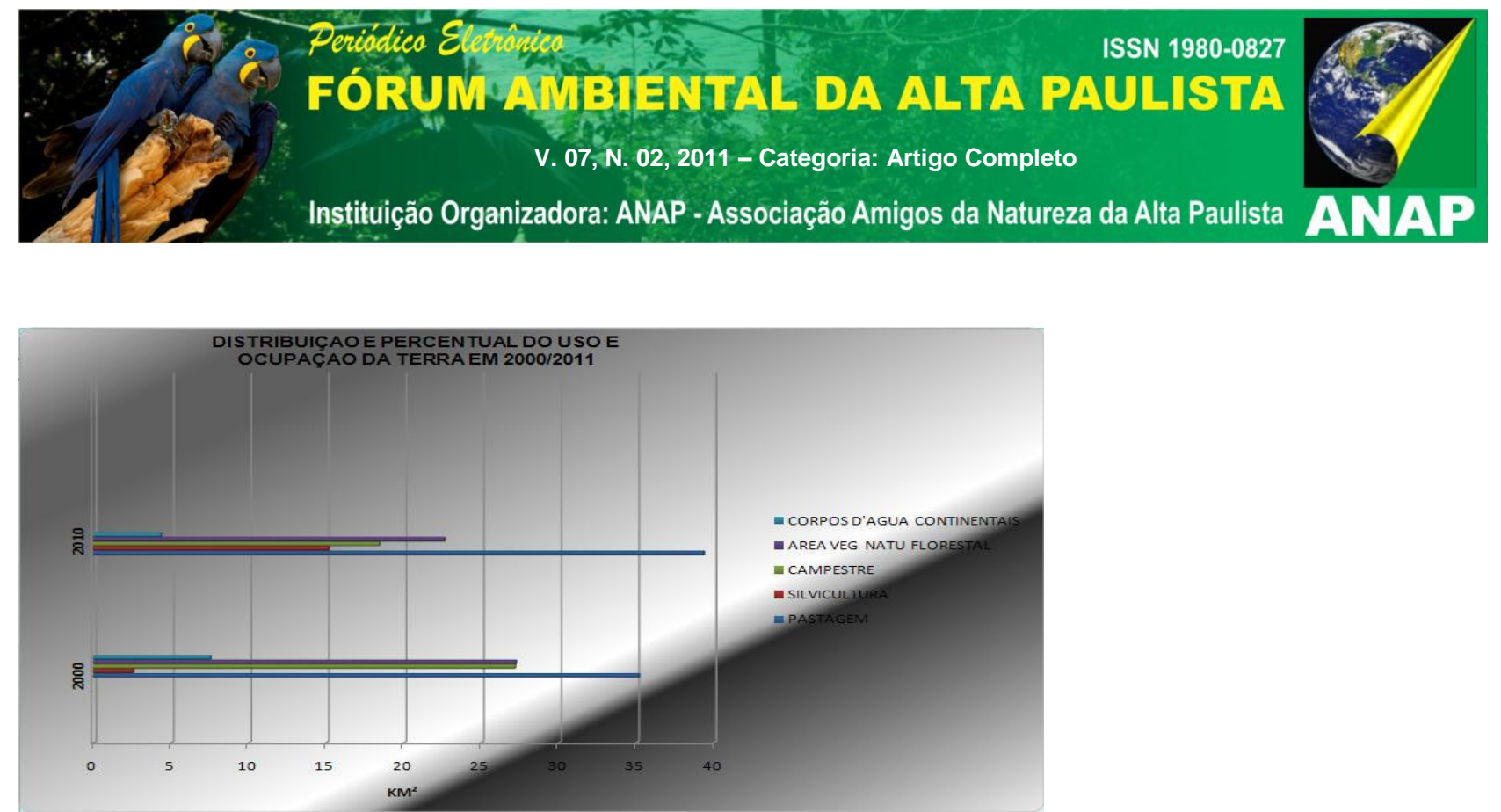

Gráfico 1: Uso e cobertura da terra em 2000/2011.

A partir dos resultados, podemos observar que na BHCC no ano de 2000 e 2011, predominou-se o uso de Pastagem e Vegetação Campestre, já que os mesmos são usados como área de pecuária. A produção de eucalipto é outra realidade que está se observando na bacia hidrográfica, com a chegada de empresas como a FIBRIA, localizada na cidade de Três Lagoas - MS, os plantios dessas mudas estão cada vez mais presentes na região, portanto, a classe da Silvicultura em relação 2000 e 2011, obteve um aumento de aproximadamente $28,27 \mathrm{~km}^{2}$ (12.62\%), ocupando área de vegetação campestre e vegetação florestal.

Em Vegetação Natural Florestal, foram consideradas florestas, área de reservas legais e matas ciliares que estão presentes em torno do córrego das Cruzes e seus afluentes. Percebe-se um retrocesso de aproximadamente $4,62 \% \%$, perdendo uma área de $10.34 \mathrm{~km}^{2}$, consequente do avanço das pastagens e silvicultura.

Após a delimitação de APP's na BHCC, identificou-se 16 nascentes que alimentam e garante sobrevivência ao córrego. Destas, a partir da nascente principal, oito se encontram na margem direita e sete na margem esquerda, assim, abrangendo uma área total de 0,8 $\mathrm{km}^{2}(0,35 \%)$ na bacia hidrográfica córrego das Cruzes.

Tabela 3: Categorias APP.

\begin{tabular}{|l|l|l|}
\hline CATEGORIA & ÁREA $\left(\mathbf{K M}^{2}\right)$ & $\%$ \\
\hline APP de Nascente & 0,8 & 0,35 \\
\hline
\end{tabular}




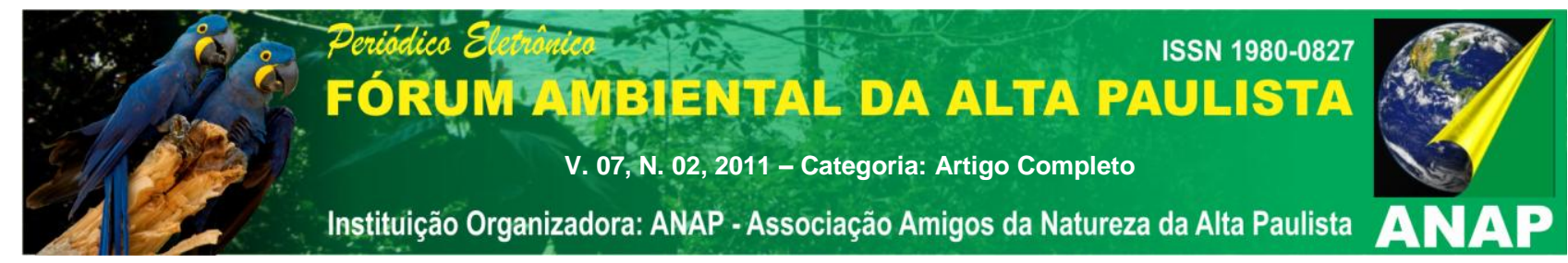

Seguindo um pensamento de proteção das nascentes, Calheiros et al. (2004) colocam que quando proíbe-se a ocupação da APP de nascente é que evite-se com um cultivo, por exemplo, que a nascente fique sujeita à erosão e que as atividades agrícolas de preparo do solo, adubação, plantio, cultivos, colheita e transporte dos produtos levem trabalhadores, máquinas e animais de tração para o local.

Quando se permite o acesso a animais nas nascentes, Calheiros et al. (2004) argumentam que "o pisoteio torna a superfície do solo próximo às nascentes. Compactado, diminui sua capacidade de infiltração, ficando sujeito à erosão laminar e, consequentemente, provocando a contaminação da água por partículas do solo, podendo provocar até mesmo soterramento da nascente". Inúmeras são as vantagens de se preservar as nascentes com relação à taxa de assoreamento, da mesma forma que as matas ciliares também têm uma função ambiental muito importante.

Entretanto, através do mapa gerado da BHCC, nota-se que a maioria das nascentes não estão protegidas pelas suas áreas de vegetação, comprometendo a sua existência e importância para bacia hidrográfica.

Das dezesseis nascentes existente no córrego, apenas a "APP 9" esta com sua área total vegetada,pelo fato de todas as nascentes estar presentes em propriedades privadas (Fazendas, Sítios e Chácaras), a maioria se encontram inseridas nas áreas de vegetação campestre (APP16, 04, 01, 11, 10, 12, 14,06, 05, 02, 07 e 15), que juntos com as áreas de pastagens (APP3, 13 e 08) são usadas pelos pecuaristas como criação de gados, onde se não protegidas, podem ocorrer o pisoteio, assim, causando problemas para a mesma.

\section{CONCLUSÕES}

Ao se estudar as APP's dentro de uma bacia hidrográfica, são importantes que se entenda como o homem, com a sua dinâmica social, se apropriou destes espaços e os transformou por meio de seu trabalho, alterando os fluxos de matéria e energia no ambiente 


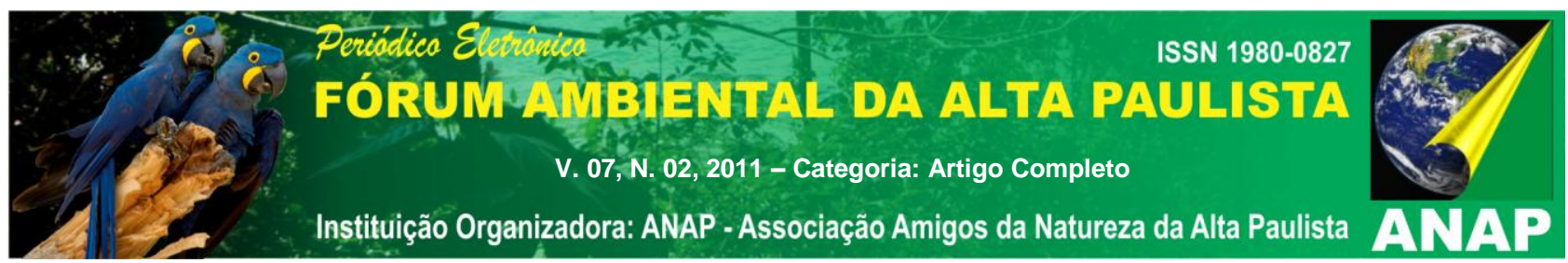

que ele se adequou. Algumas modalidades estarão mais degradadas do que outras, variando de um lugar para o outro, e a partir disso pode-se propor medidas prioritárias à recuperação das APP's mais degradadas.

O uso conjugado das geotecnologias é elemento essencial para determinar o tipo de uso e ocupação da terra e identificação de APP em toda extensão da bacia do Córrego das Cruzes, pois a aquisição, manipulação e armazenamentos dos dados da área de estudo foram processados e transformados em informações que podem subsidiar o planejamento da área.

O mapa gerado com as áreas das classes temáticas permitiu quantificar e avaliar a dinâmica do ambiente em que ocorreu na BHCC no ano de 2000 e 2011 e a situação atual das APP's de nascentes no âmbito geográfico.

\section{BIBLIOGRAFIA}

FERREIRA, C.C. Uso de imagens de sensoriamento remoto para mapeamento do uso e ocupação da terra da Bacia Hidrográfica do Alto Sucuriú- MS-BR. II Simpósio Internacional da Cartografia na Geografia. São Paulo. 2010.

FITZ, P.R. Geoprocessamento Sem Complicação. São Paulo: Oficina de Textos, 2008.

FLORENZANO, T. G. Imagens de Satélite para Estudos Ambientais. São Paulo: Oficina de textos, 2002.

IBGE. Instituto Brasileiro de Geografia e Estatística. Manual Técnico de Uso da Terra. 2ª edição. $n^{\circ}$ 7. Rio de Janeiro, 2006.

IBGE. Manual Técnico do Uso da Terra. Ed. 2, n. 7. Rio de Janeiro, 2006.

INPE.(Instituto Nacional de Pesquisas Espaciais). Imagem LANDSAT TM, Órbita 224, ponto 074 e 075 - 13/06/2006 e 11/06/2009. Departamento de Geração de Imagens. 


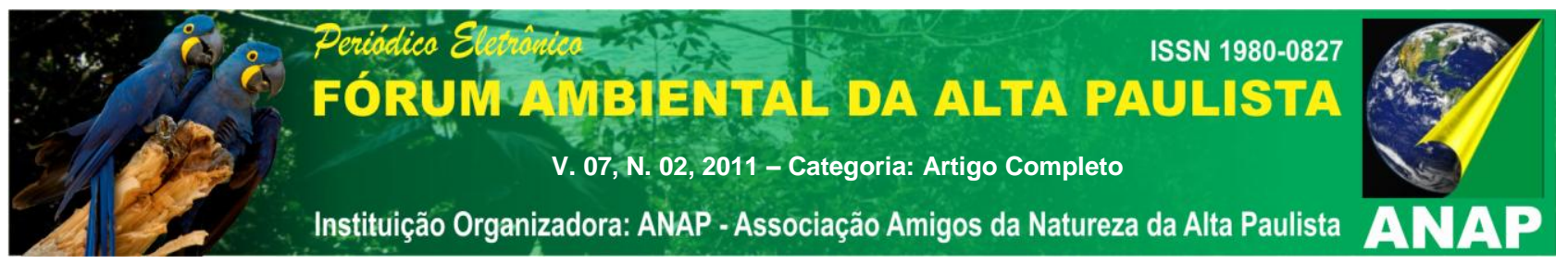

MENDONÇA, Franscisco. et al. O espaço geográfico em análise. In: RA'E GA. v.1 Curitiba: Departamento de Geografia/UFPR, 1997

PEREIRA, Gilberto Corso e ROCHA, Maria C. Furtado. Dados Geográficos aspectos e perspectivas. LCAD, UFBA - Faculdade de Arquitetura. Salvador, 2002.

CUNHA, S. B.; GUERRA, A. J. T. Degradação Ambiental. In: CUNHA, S. B.; GUERRA, A. J. T. (orgs) Geomorfologia uma atualização de bases e conceitos. $4^{\underline{a}}$ ed. Rio de Janeiro: Bertrand Brasil, 2003. 